\title{
The relationship between the visceral adiposity index and carotid atherosclerosis in different genders and age groups
}

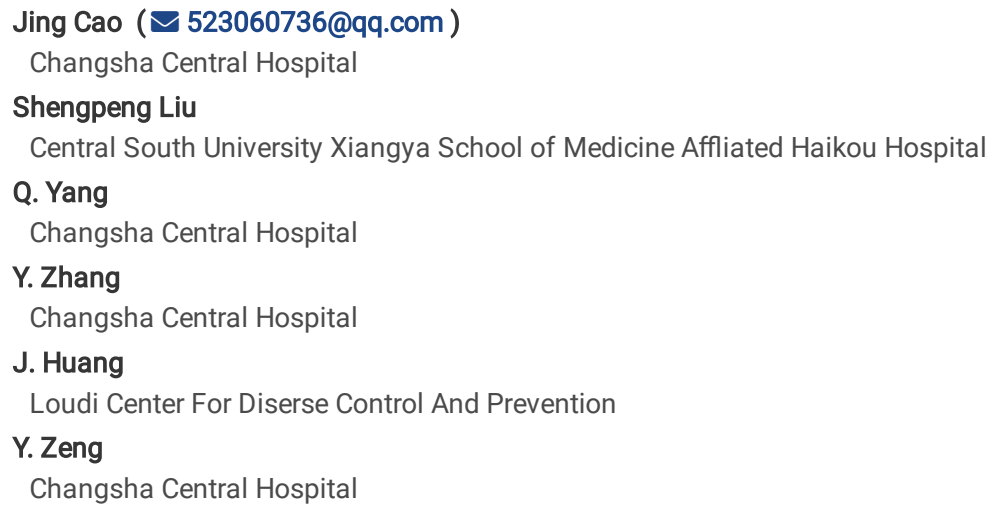

Version of Record: A version of this preprint was published at Saudi Medical Journal on February 1st, 2022. See the published version at https://doi.org/10.15537/smj.2022.43.2.20210824. 


\section{Abstract}

Objective: We aimed to investigate the possible relationship between visceral adiposity index (VAI) and carotid atherosclerosis(CAS) in different genders and age groups in China.

Methods: This study was an observational cross-sectional study and included 1996 participants who were health examination population .From January 2018 to June 2019, people over 18 years old who had physical examinations were included in the study. Each participant completed a standard questionnaire, anthropometric measurements, ultrasonic examination, and provided blood samples for biochemical measurements. Regression models were utilized to evaluate the correlation between VAI and the CAS risk. An ROC curve was utilized to predict VAl diagnostic efficacy for carotid atherosclerosis.

Result: After adjusting for potential risks, high-VAl subjects had an increased OR of having CAS in women aged $>44$ years[OR=3.09,95\% Confdence interval $(95 \% \mathrm{Cl})=1.64 \otimes 5.82, \mathrm{p}<0.001]$. In females, the AUC and sensitivity specificity were $[(0.595,76.68 \%$ and $39.85 \%$, all females $),(0.575,78.51 \%$ and $30.37 \%$, age $\leq 44),(0.609,84.71 \%$ and $40.46 \%$, age $>44)$. When compared with traditional obesity indices(BMI, WC, and $\mathrm{HC})$, the predictive ability of VAl was stronger in females $>44$. The same relationships in males were not signifcant.

Conclusions: The VAI were associated with an increased risk of CAS, and it could be selected as new and simple predictors of CAS for middle-aged and elderly women(age >44)in China .

\section{Introduction}

Cardiovascular and cerebrovascular diseases(CCVD)are the top two causes of death in China. The number of years lost due to cardiovascular and cerebrovascular diseases is more than 2 years old every year, which seriously affects resident health and heavily burdens society and the economy ${ }^{[1]}$ Atherosclerosis is one of the most important cardiovascular and cerebrovascular disease causes ${ }^{[2]}$. The carotid artery is superficially located, carotid atherosclerosis(CAS) reliably correlates with cardiovascular and cerebrovascular disease ${ }^{[3]}$; it is a window for the formation and evolution of atherosclerosis in coronary artery, cerebral artery, and other artery. Early identification of high-risk groups of carotid atherosclerosis(CAS) can delay or prevent cardiovascular and cerebrovascular diseases from occurring.

Obesity, has been generally considered to be a key correlate in the pathogenesis of diabetes, hypertension (HTN), and cardiovascular disease(CVD) ${ }^{[4]}$.Current evidence has revealed that the clinical risk attributable to obesity depends not simply on the extent, but importantly, the distribution of the excess adiposity ${ }^{[5]}$ .Moreover, visceral fat accumulation, may exert more detrimental effects on CVD risks than general fat accumulation. Traditional adiposity-based indices, such as waist circumference (WC), body mass index (BMI), and hip circumference( $\mathrm{HC}$ ) are common indicators for the evaluation of obesity worldwide, but fat distribution and visceral fat function are not considered ${ }^{[6]}$,and has not proven to be a predictor of cardiovascular events or mortality in some large cohorts ${ }^{[7,8]}$.

The visceral adiposity index (VAl) was proposed by Amato et al. ${ }^{[9]}$ in 2010, which combines WC, BMI, and blood lipids and indirectly reflects visceral fat function and insulin resistance, especially for normal or lean bodied people. Subsequently, several studies reported that visceral adiposity index was a more accurate indicator than other simple anthropometric measures, such as BMI and so on, in predicting incident diabetes and CVD events ${ }^{[10,11]}$. In addition, Johnson W and Lopez AA et al. ${ }^{[12,13]}$ proposed that VAI has been associated with prognostic value in the evaluation of cardiovascular risk. However, the relationship between the visceral adiposity index and carotid atherosclerosis, and the ability of VAI to predict CAS in different genders and age groups, have not ever been reported . Hence, the aim of our study was to explore the correlation between VAl and carotid atherosclerosis in the Chinese population of different genders and ages groups, as well as whether it can be utilized to effectively predict CAS.

\section{Materials And Methods}

\subsection{Study population}

This study was an observational cross-sectional study. A total of 1996 participants were enrolled from the Changsha hospital physical examination center, from January 2018 to June 2019. Inclusion criteria: aged $\geqq 18$ years; those who had lived in the local area for more than 6 months over the past 12 months. Exclusion criteria: liver and kidney dysfunction, or complicated malignant tumors; hormone and lipid-lowering drug use within half a year; patients with mental disorders or cognitive and language communication disorders; and pregnant women.

All subjects agreed to participate in this study and gave informed consent. This study was approved by the institutional review board of Changsha Central Hospital of Medicine and complied with the Helsinki declaration.

\subsection{Date collection}

A standardized questionnaire was utilized to obtain baseline demographic information, such as age, gender, family history of diabetes, smoking status, physical activity, and so on. Anthropometric measurements included body weight, body height, WC, and blood pressure. Body weight and height were measured on an empty stomach via standard methods and each was recorded to the nearest $0.1 \mathrm{~kg}$ and $0.1 \mathrm{~cm}$, whereas BMI was calculated as the weight in kilograms divided by the square. The WC was measured twice at one $\mathrm{cm}$ above the umbilicus level during minimal respiration. The hip circumference (HC) was measured at the highest point of the hip or the level of the trochanter of the femur. Systolic blood pressure (SBP) and diastolic blood pressure (DBP) were examined three times at $30 \mathrm{~s}$ intervals by trained doctors who utilized a standardized mercury sphygmomanometer on both arms after resting for 5 min in a sitting position at the height in meters. Laboratory examinations, including total cholesterol, high-density lipoprotein cholesterol (HDL-C), low-density lipoprotein cholesterol (LDL-C), triglyceride (TG), and fasting plasma glucose (FPG) were conducted. Blood samples were collected in the morning after 
overnight fasting for at least $8 \mathrm{~h}$. All of the collected blood samples were measured via an automatic biochemical analyzer of the same model as that in the hospital laboratory.

\subsection{Ultrasonic examination}

An ACUSON 128XP/10 color Doppler ultrasonic detector and arterial health package(AHP) was utilized in the present study, and the probe frequency was set at $7-15 \mathrm{mhz}$. The subjects were placed in the supine position. According to the vascular ultrasound examination guidelines ${ }^{[14]}$, the scanning sections included both the transverse and longitudinal sections. The Angle and position of the probe were fixed by vascular angle locator, and the dynamic images of the common carotid artery (CCA), the Bulb, and the internal carotid artery (ICA) with a range of $10 \mathrm{~mm}$ were collected and stored by electrocardiogram simultaneously. Since the absolute value of IMT is small, subtle differences can affect patient risk stratification $\square$ Therefore, Arterial Health Package was used in this group ${ }^{[15]}$,in the $2 \mathrm{D}$ gray scale mode, by collecting the original digital audio image, phase analysis and processing of the original data of the vessel wall radio frequency signal, extract the image of the carotid inner intima and automatically measure the IMT $\square$ and the mean value was obtained after six measurements .According to the standard of American Heart Association(AHA) ${ }^{[16]}$, the subjects were divided into two groups: the hardening group (IMT $\geq 1.0$ $\mathrm{mm}$ ) and the normal group (IMT cript > $1.0 \mathrm{~mm}$ ).

\subsection{VAl calculation method}

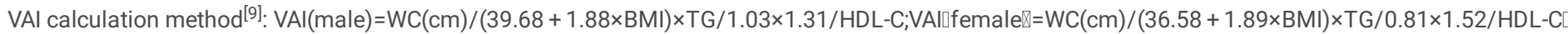

\subsection{Related diagnosis/index definition}

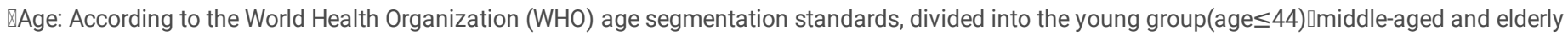
group $\llbracket$ age $>44 \rrbracket^{[17]} . \llbracket$ Criteria for hypertension diagnosis: refer to the 2017 American ACC/AHA guidelines: systolic/diastolic blood pressure greater than $130 / 80 \mathrm{mmHg}$, taking hypotensive drugs ${ }^{[18]}$, or those diagnosed by previous medical institutions. $\otimes$ The diagnostic criteria for diabetes: Chinese guidelines for type 2 diabetes prevention and treatment (2017 Edition), with fasting blood glucose $\geq 7.0 \mathrm{mmol} / \mathrm{L}$ or previously diagnosed with diabetes in medical

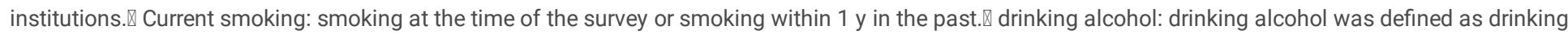
four times per month in the past six months. $\otimes$ Exercise $\geq 3$ times / week :exercise more than or equal to 3 times within a week, and each exercise time more than 30 minutes. Eating habits are salty: the index was calculated according to total salt consumption per month/number of family members/days of the month, and the daily salt intake $>6 \mathrm{~g}$ was defined as salty eating habits.

\subsubsection{Statistical Analysis}

The STATA version 13.0 statistical software were utilized to analyze the data. The continuous normal distribution data were expressed via the mean plus-orminus the standard deviation, and the comparison between the groups was conducted via one-way ANOVA; the continuous non-normal distribution data were represented via median ( 25 quartiles, 75 quartiles), and the comparison between the groups was conducted via the Kruskal Wallis $\mathrm{h}$ test. The number of cases (rate) was utilized to express the count data, and the chi-square test was utilized to make comparisons between the groups. The VAI was divided into three groups according to the three quartiles. The carotid atherosclerosis risk in different VAl groups was analyzed via binary logistic regression. The CAS diagnostic ability was defined by the area under the curve in the ROC analyses, and the optimal cut-off value was determined via maximal the Youden index. Comparisons of the area under the receiver operating characteristics curve (AUROC) between visceral adiposity index and other adiposity-based measurements (BMI, WC, HC) were conducted by using the z-statistics. A two-tailed $P$ value of $<0.05$ was regarded as statistically significant.

\section{Results}

\subsection{Gender Characteristics stratified by VAl}

Men and women were divided into three groups according to the VAl tertile (Tertile 1, 2, 3). In women, BMI, WC $\square \mathrm{HC} \square T$ otal cholesterol $\square T$ riglyceride $\square \mathrm{HDL}-\mathrm{C} \square \mathrm{LDL}-\mathrm{C} \square$ FPG Diabetes Mellitus $\square$ and current smoking were significantly different among the VAl tertile $(P<0.05)$; In men,significant differences were found among the

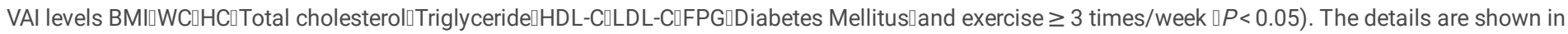
Table 1. 
Table 1

Characteristics of patients stratified by VAl tertiles

\begin{tabular}{|c|c|c|c|c|c|c|c|c|}
\hline \multirow[t]{2}{*}{ VAl Characteristics } & \multicolumn{3}{|l|}{ Female } & \multirow{2}{*}{$\begin{array}{l}P \\
\text { value }\end{array}$} & \multicolumn{3}{|l|}{ Male } & \multirow{2}{*}{$\begin{array}{l}P \\
\text { value }\end{array}$} \\
\hline & $\begin{array}{l}\text { Tertile } 1(< \\
1.33)\end{array}$ & $\begin{array}{l}\text { Tertile 2(1.33 } \\
\text { to } 2.43)\end{array}$ & $\begin{array}{l}\text { Tertile 3( } \geq \\
2.44)\end{array}$ & & $\begin{array}{l}\text { Tertile } 1 \text { (< } \\
0.91)\end{array}$ & $\begin{array}{l}\text { Tertile } 2(1.33 \\
\text { to } 2.43)\end{array}$ & $\begin{array}{l}\text { Tertile 3( } \geq \\
2.44)\end{array}$ & \\
\hline No. of cases & 378 & 382 & 376 & & 285 & 287 & 291 & \\
\hline Age (years), $X \pm S$ & $45.7 \pm 16.97$ & $48.45 \pm 16.32$ & $47.86 \pm 16.59$ & 0.057 & $44.42 \pm 16.93$ & $47.29 \pm 18.78$ & $45.57 \pm 17.66$ & 0.153 \\
\hline $\begin{array}{l}\text { Body mass index } \\
\left(\mathrm{kg} / \mathrm{m}^{2}\right) ; X \pm S\end{array}$ & $22.86 \pm 3.64$ & $23.42 \pm 3.82$ & $24.66 \pm 4.34$ & $<.001$ & $22.66 \pm 3.74$ & $23.78 \pm 4.02$ & $24.42 \pm 4.23$ & $\begin{array}{l}< \\
0.001\end{array}$ \\
\hline $\begin{array}{l}\text { Waist circumference } \\
(\mathrm{cm}),{ }^{\prime} \mathrm{X} \pm \mathrm{S}\end{array}$ & $73.13 \pm 10.22$ & $75.13 \pm 10.29$ & $75.87 \pm 9.93$ & 0.001 & $75.17 \pm 10.86$ & $76.68 \pm 10.67$ & $78.78 \pm 10.59$ & $<.001$ \\
\hline $\begin{array}{l}\text { hip circumference } \\
\text { (cm), } X \pm S\end{array}$ & $89.14 \pm 8.63$ & $90.48 \pm 8.18$ & $90.69 \pm 7.89$ & 0.020 & $88.55 \pm 7.34$ & $88.67 \pm 8.31$ & $90.32 \pm 8.51$ & 0.013 \\
\hline $\begin{array}{l}\text { Total cholesterol } \\
(\mathrm{mmol} / \mathrm{L}),{ }^{\prime} \mathrm{X} \pm \mathrm{S}\end{array}$ & $4.91 \pm 0.87$ & $5.14 \pm 0.97$ & $5.23 \pm 0.96$ & $<.001$ & $4.98 \pm 0.91$ & $5.13 \pm 0.95$ & $5.2 \pm 0.99$ & 0.016 \\
\hline $\begin{array}{l}\text { Triglyceride } \\
\text { (mmol/L),M(P25,P75) }\end{array}$ & $0.80(0.65,0.94)$ & $1.29(1.08,1.51)$ & $2.25(1.84,3.07)$ & $\begin{array}{l}< \\
0.001\end{array}$ & $0.81(0.64,0.95)$ & $1.30(1.11,1.51)$ & $2.19(1.77,2.76)$ & $\begin{array}{l}<.001 \\
0.001\end{array}$ \\
\hline HDL-C (mmol/L); $X \pm S$ & $1.59 \pm 0.33$ & $1.28 \pm 0.24$ & $1.06 \pm 0.18$ & $<.001$ & $1.64 \pm 0.36$ & $1.26 \pm 0.22$ & $1.07 \pm 0.17$ & $\begin{array}{l}<.001 \\
0.001\end{array}$ \\
\hline LDL-C (mmol/L); $X \pm S$ & $2.91 \pm 0.76$ & $3.29 \pm 0.86$ & $3.10 \pm 0.88$ & $<.001$ & $2.9 \pm 0.78$ & $3.29 \pm 0.87$ & $3.14 \pm 0.93$ & $\begin{array}{l}<.001 \\
0.001\end{array}$ \\
\hline FPG $(\mathrm{mmol} / \mathrm{L}) ; \mathrm{X} \pm \mathrm{S}$ & $4.98(4.71,5.36)$ & $5.09(4.74,5.43)$ & $5.26(4.94,5.80)$ & $<.001$ & $4.99(4.52,5.29)$ & $5.15(4.57,5.48)$ & $5.24(4.93,5.53)$ & $<.001$ \\
\hline $\begin{array}{l}\text { Family history of } \\
\text { hypertension, } \mathrm{n}(\%)\end{array}$ & $99(26.19)$ & 116(30.37) & $96(25.53)$ & 0.269 & $72(25.26)$ & $60(20.91)$ & $77(26.46)$ & 0.262 \\
\hline $\begin{array}{l}\text { Family history of } \\
\text { Diabetes Mellitus, } n \\
\text { (\%) }\end{array}$ & $17(4.50)$ & $20(3.95)$ & 12(9.92) & 0.374 & $13(4.56)$ & $9(3.14)$ & $16(5.50)$ & 0.379 \\
\hline Hypertension, n (\%) & $168(44.44)$ & 186(48.69) & $189(50.27)$ & 0.254 & $131(45.96)$ & 138(48.08) & 153(52.58) & 0.268 \\
\hline $\begin{array}{l}\text { Diabetes Mellitus, } \mathrm{n} \\
(\%)\end{array}$ & $41(11.02)$ & $49(12.83)$ & $66(17.55)$ & 0.028 & $29(10.18)$ & $31(26.72)$ & $56(19.24)$ & 0.002 \\
\hline $\begin{array}{l}\text { Current smoking, } \mathrm{n} \\
(\%)\end{array}$ & $5(1.32)$ & 10(1.98) & 19(15.7) & 0.009 & $140(49.12)$ & $128(44.6)$ & 134(46.05) & 0.542 \\
\hline Daily drinking, n (\%) & $9(2.38)$ & $13(2.57)$ & $18(14.88)$ & 0.198 & $114(40)$ & 104(36.24) & 118(40.55) & 0.513 \\
\hline $\begin{array}{l}\text { Tea drinking } \geq 5 \\
\text { times / week,n (\%) }\end{array}$ & 118(31.22) & 136(35.60) & 136(36.17) & 0.292 & 145(50.88) & 152(52.96) & 167(57.39) & 0.188 \\
\hline $\begin{array}{l}\text { Exercise } \geq 3 \text { times / } \\
\text { week,n }(\%)\end{array}$ & 105(27.78) & $123(24.31)$ & 102(27.12) & 0.246 & $70(24.56)$ & 101(35.19) & $84(28.87)$ & 0.020 \\
\hline $\begin{array}{l}\text { Eating habits are } \\
\text { salty,n (\%) }\end{array}$ & $99(26.19)$ & $85(16.8)$ & 101(26.86) & 0.285 & $80(28.07)$ & $91(31.71)$ & $83(28.52)$ & 0.581 \\
\hline $\begin{array}{l}\text { Like pickled food,n } \\
(\%)\end{array}$ & $39(10.32)$ & 42(8.30) & $34(28.10)$ & 0.665 & $19(6.67)$ & $26(9.06)$ & 23(7.90) & 0.569 \\
\hline $\begin{array}{l}\text { Sweets } \geq 3 \text { times / } \\
\text { week,n (\%) }\end{array}$ & $64(16.93)$ & $62(12.25)$ & $54(14.36)$ & 0.607 & $51(17.89)$ & $64(22.30)$ & $56(19.24)$ & 0.399 \\
\hline $\begin{array}{l}\text { Working hours over } \\
10 \text { hours / day,n (\%) }\end{array}$ & $10(2.65)$ & $20(3.95)$ & $19(15.70)$ & 0.147 & 23(8.07) & $22(7.67)$ & $37(12.71)$ & 0.071 \\
\hline
\end{tabular}

\subsection{Relationship between VAl and CAS in different genders}

When compared with the low tertile (VAl tertile 1), the unadjusted model OR for CAS in VAl tertile 2 and VAl tertile 3 (female: OR = 1.99 and 2.26; males: OR = 1.40 and 1.44).Further adjustment for relevant confounding factors, including BMI,WC, et al. VAI tertile $2(\mathrm{OR}=2.16,95 \% \mathrm{Cl}$ : $1.51-3.08)$ and VAI tertile $3(\mathrm{OR}=$ 2.44,95\% Cl: 1.50-3.98) demonstrated increased CAS risk in females when compared to individuals within the VAl tertile 1. In contrast, we found no such association in males (VAl tertile 2 : $\mathrm{OR}=1.47,95 \% \mathrm{Cl}=0.97-2.23, P=0.071$; VAl tertile 3 : $\mathrm{OR}=1.74,95 \% \mathrm{Cl}=1.05-3.16, P=0.056$ vs. tertile 1 ). The details are shown in Table 2. 
Table 2

Relationship between VAl and CAS in different genders

\begin{tabular}{|c|c|c|c|c|}
\hline & \multicolumn{2}{|l|}{ Model one } & \multicolumn{2}{|l|}{ Model two } \\
\hline & $\mathrm{OR}(95 \% \mathrm{Cl})$ & $P$-value & $\mathrm{OR}(95 \% \mathrm{Cl})$ & $P$ value \\
\hline \multicolumn{5}{|l|}{ Female } \\
\hline Tertile 1 & Reference & & Reference & \\
\hline Tertile 2 & $1.99(1.48 \otimes 2.67)$ & $<0.001$ & $2.16(1.51 \llbracket 3.08)$ & $<0.001$ \\
\hline Tertile 3 & $2.26(1.68 \bowtie 3.03)$ & $<0.001$ & $2.44(1.50 \llbracket 3.98)$ & $<0.001$ \\
\hline \multicolumn{5}{|l|}{ male } \\
\hline Tertile 1 & Reference & & Reference & \\
\hline Tertile 2 & $1.40(1.01 \otimes 1.95)$ & 0.044 & $1.47(0.97 \llbracket 2.23)$ & 0.071 \\
\hline Tertile 3 & $1.44(1.04 \llbracket 2.00)$ & 0.029 & $1.74(1.05 \llbracket 3.16)$ & 0.056 \\
\hline
\end{tabular}

\subsection{Relationship between VAI and CAS in female of different age groups}

For aged $\leq 44$ females in the unadjusted model, the highest VAl tertile was associated with carotid atherosclerosis risk $(\mathrm{OR}=1.75,95 \% \mathrm{Cl}: 1.10-2.80, P=0.019$ vs. tertile 1); after adjusting for confounding factors, the correlation disappeared. For aged $>44$ females, when compared to individuals within the VAl tertile 1 in the unadjusted model, the OR of tertile 2 and tertile 3 were 2.17 (95\% Cl: $1.50-3.19)$ and 2.68 (95\% Cl: 1.81-3.97); for the further adjustment model, the OR in tertile2 and tertile 3 were 2.42 (95\% Cl: $1.53-3.82)$ and 3.09 (95\% Cl: $1.64-5.82)$. The details are shown in Table 3.

Table 3

Relationship between VAI and CAS in female of different ages

\begin{tabular}{|c|c|c|c|c|}
\hline & \multicolumn{2}{|l|}{ Model one } & \multicolumn{2}{|l|}{ Model two } \\
\hline & OR(95\%Cl) & $P$-value & OR(95\%Cl) & $P$-value \\
\hline \multicolumn{5}{|l|}{ age $\leq 44$} \\
\hline Tertile 1 & Reference & & Reference & \\
\hline Tertile 2 & $1.59(0.99 \bowtie 2.56)$ & 0.060 & $1.54(0.85 \rrbracket 2.79)$ & 0.156 \\
\hline Tertile 3 & $1.75(1.10 \otimes 2.80)$ & 0.019 & $1.52(0.67 \rrbracket 3.44)$ & 0.315 \\
\hline \multicolumn{5}{|l|}{ age $₫ 44$} \\
\hline Tertile 1 & Reference & & Reference & \\
\hline Tertile 2 & $2.17(1.50 \otimes 3.19)$ & $<0.001$ & $2.42(1.53 \llbracket 3.82)$ & $<0.001$ \\
\hline Tertile 3 & $2.68(1.81 \llbracket 3.97)$ & $<0.001$ & $3.09(1.64 \rrbracket 5.82)$ & $<0.001$ \\
\hline
\end{tabular}

\subsection{Relationship between VAI and CAS in male of different age groups}

In men aged $\leq 44$, VAI was not found to be associated with carotid atherosclerosis risk. For aged $\mathbb{4} 4$ males in the unadjusted model,the highest tertile (VAI tertile 3$)$ was signifcantly associated with $\mathrm{CAS}(\mathrm{OR}=1.86,95 \% \mathrm{Cl}=1.17-2.95, \mathrm{P}=0.009)$. However, VAl tertile did not impact on the risk of CAS in adjusted model. The details are shown in Table 4. 
Table 4

Relationship between VAI and CAS in male of different ages

\begin{tabular}{|c|c|c|c|c|}
\hline & \multicolumn{2}{|l|}{ Model one } & \multicolumn{2}{|l|}{ Model two } \\
\hline & $\mathrm{OR}(95 \% \mathrm{Cl})$ & $P$-value & $\mathrm{OR}(95 \% \mathrm{Cl})$ & $P$-value \\
\hline \multicolumn{5}{|l|}{ age $\leq 44$} \\
\hline Tertile 1 & Reference & & Reference & \\
\hline Tertile 2 & $1.41(0.86 \llbracket 2.29)$ & 0.172 & $1.716(0.90 \bowtie 3.26)$ & 0.099 \\
\hline Tertile 3 & $1.23(0.75 \llbracket 2.01)$ & 0.407 & $2.44(0.832 \rrbracket 4.64)$ & 0.124 \\
\hline \multicolumn{5}{|l|}{ age $₫ 44$} \\
\hline Tertile 1 & Reference & & Reference & \\
\hline Tertile 2 & $1.40(0.88 \llbracket 2.20)$ & 0.153 & $1.65(0.94 \llbracket 2.90)$ & 0.084 \\
\hline Tertile 3 & $1.86(1.17 \rrbracket 2.95)$ & 0.009 & $2.00(0.95 \rrbracket 4.42)$ & 0.069 \\
\hline
\end{tabular}

\subsection{Prediction effect of VAl based on the ROC curve on CAS in different populations}

The ability of VAl to predict CAS in different populations was determined by analyzing the receiver operating characteristic (ROC) curves. All of the subject groups were in the areas under the ROC curves (AUC) for the VAI $(0.561,95 \% \mathrm{Cl}=0.535-0.586)$. To understand the VAI predictive effect on CAS in different populations, all of the populations were further analyzed according to gender and age. In females, ages $₫ 44$ were the areas under the ROC curves (AUC $=0.609$, $95 \% \mathrm{Cl}: 0.566-0.653, P<0.001)$ for the VAl that were higher than females aged $\leq 44(\mathrm{AUC}=0.575,95 \% \mathrm{Cl}: 0.520-0.629, P<0.001)$. In contrast, the VAl was found to have no predictive value for CAS in males. The optimal cut-off values for the VAl levels of all of the subject groups were 0.90 (sensitivity $=57.00 \%$, specificity $=89.01 \%$ ). The optimal cut-off values for the VAl levels in all of the females were 1.60 (sensitivity $=76.68 \%$, specificity $=39.84 \%$ ), females aged $\leq 44$ were 1.35 (sensitivity $=78.51 \%$, specificity $=30.37 \%$ ), and females aged $₫ 44$ were 1.61 (sensitivity $=84.71 \%$, specificity $=40.46 \%$ ). The details are shown in Table 5.

Table 5

Prediction of ROC curve of CAS by VAl in different population

\begin{tabular}{|c|c|c|c|c|c|}
\hline \multirow[t]{2}{*}{ Different populations } & \multirow[t]{2}{*}{ AUC } & \multirow[t]{2}{*}{ std. errors } & \multirow[t]{2}{*}{$P$-value } & \multicolumn{2}{|l|}{$95 \% \mathrm{Cl}$ for AUC } \\
\hline & & & & Lower Bound & Upper Bound \\
\hline All subject groups & 0.561 & 0.013 & $<0.001$ & 0.535 & 0.586 \\
\hline All females & 0.595 & 0.017 & $<0.001$ & 0.562 & 0.628 \\
\hline Female aged $\leq 44$ years & 0.575 & 0.028 & 0.008 & 0.520 & 0.629 \\
\hline Female aged $\mathbb{\Delta 4 4}$ years & 0.609 & 0.022 & $<0.001$ & 0.566 & 0.653 \\
\hline All males & 0.537 & 0.020 & 0.060 & 0.499 & 0.575 \\
\hline Male aged $\leq 44$ years & 0.514 & 0.029 & 0.640 & 0.457 & 0.570 \\
\hline Male aged $\varangle 44$ years & 0.553 & 0.027 & 0.056 & 0.499 & 0.606 \\
\hline
\end{tabular}

To further understand the VAI predictive effect for carotid atherosclerosis in women, the ROC curves were plotted to evaluate the predictive values of different obesity indices including VAl, BMI, WC, and HC. In females aged $>44$ years, the areas under the ROC curves (AUC) for the VAI ( $0.609,95 \% \mathrm{Cl}=0.566-0.653, P<$ 0.001 ) were higher than those for the BMI, WC, and $\mathrm{HC}($ all $P<0.001)$. There was no significant difference in the predictive effect of VAl on CAS compared with $\mathrm{BIM}, \mathrm{WC}$ and $\mathrm{HC}$ in total women population and other women subgroups. The details are shown in Fig. 1.

\section{Discussion}

The present study assessed the VAI with the carotid atherosclerosis (CAS)occurrence in the Chinese population. Results showed a gradual increase in CAS with increasing VAI in females; after adjusting for the potential risk factors, an elevated CAS risk associated with the VAI was evident for females aged $>44$, and but not consistently in males. The ROC analysis confirmed the VAI may be a useful biomarker for identifying CAS in women, especially for middle-aged and elderly women, and its predictive power was better than other obesity indicators. However, no such value was found in males.

In China with rapid economic growth, the lifestyles of people have also changed, with a sedentary lifestyle, lack of exercise, and high-calorie diets increasing ${ }^{[19]}$. According to the results of chronic diseases and risk factors in China in 2013 , the overweight and obesity rates of Chinese adults reached $46.5 \%$ [20.21], and the overweight and obesity rates of children also reached $16.0 \%{ }^{[20.22]}$. In the past 10 years, the overweight and obesity rates of Chinese residents 
have significantly increased, even surpassing those of many other developed countries ${ }^{[23]}$. Many studies have confirmed that ${ }^{[24.25]}$ the obesity prevalence is increasing, especially visceral obesity that contributed to the development and increased incidence of cardiovascular and cerebrovascular diseases, type 2 diabetes, malignant tumors, and other diseases. In most population-based studies, BMI and WC were the most commonly utilized methods to measure obesity

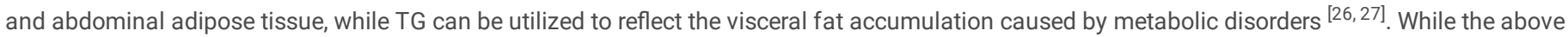
indicators have their advantages, they cannot account for the fat distribution and blood lipid levels ${ }^{[28]}$.

As surrogate markers, the VAl were initially introduced by Amato et al. ${ }^{[29]}$. BMI, WC, TG, and HDL-C are central VAl parameters utilized to assess the adipose tissue distribution and visceral fat function. Amato et al. ${ }^{[30]}$ utilized an MRI to measure the visceral fat and subcutaneous fat content in 315 physical examination population members with a BMI of $20-30 \mathrm{~kg} / \mathrm{m}^{2}$ and found that VAl closely related to visceral fat, which could predict the risk of cardiovascular metabolic diseases, especially for lean-bodied people. Mohammadreza et al. ${ }^{[31]}$ proposed that VAl was an independent predictor of cardiovascular disease, which is better than traditional indicators when it comes to predicting cardiovascular disease in women. Also, Chinese scholars ${ }^{[32,33]}$ found that VAI was an independent influencing factor of atherosclerosis, and the atherosclerosis risk increased with the VAI increase.

Herein, we found a significant association between VAI and CAS in different genders and age groups, which, to our knowledge, is the first report of this association in the literature. Results of the present study showed that the carotid atherosclerosis risk in women with high VAl levels was higher than that of low-level people; Through stratified analysis by age, this trend was found to be very significant in women aged $\nabla 44$, but this trend was not observed in women aged $\leq 44$. In contrast, we found no such association in males. The present study revealed a sex and ages specifc association between visceral adiposity and CAS. The specific reason for this difference remains unclear, and it may be related to the different distribution of sex hormones and visceral fat between men and women ${ }^{[34,35,36]}$. The average age of post-menopause in China ranged between 48 and 51 years old ${ }^{[37,38]}$. Therefore, women aged $>44$ years old in the present study could be considered as part of the perimenopause population. Women going through menopausal transition were correlated with increased adiposity via the changes of inflammatory markers and adipokines, which could be the cause of increased cardiovascular disease risk among this population ${ }^{[39]}$. In contrast, the correlation between VAl and carotid atherosclerosis was found to have disappeared in men and women aged $\leqq 44 y e a r s$, and visceral fat was positively correlated with age. Relevant studies ${ }^{[40]}$ have shown that visceral fat increased with age, and adipose tissue was more likely to accumulate in viscera and the abdomen with age. Ran et al. ${ }^{[41,42]}$ showed that when no significant difference in BMl existed between young people and quinquagenarians, the contents of visceral fat and subcutaneous fat in the elderly were significantly increased.

Among women, the area under the curve of each age group was greater than 0.5 . The VAl had the highest predictive value for CAS; it was higher than that of other obesity indicators in women aged $>44$. However, there was a lower value in men and a sex difference for VAl. Li et al. ${ }^{[36]}$ also showed this difference.

Obesity, especially visceral fat accumulation, secreted visfatin, interleukin-6, tumor necrosis factor Q, etc., cause insulin resistance ${ }^{[43]}$, which is one of the main reasons for atherosclerosis. At present, CT and MRI scans are the best methods for accurately evaluating visceral fat ${ }^{[44]}$. Domestic and foreign research results show that ${ }^{[45,46]}$ a significant correlation exists between abdominal visceral fat and arteriosclerosis via CT scanning. However, these imaging techniques are unsuitable in a general population or epidemiological research studies, due to availability, time-consuming, expense, and radiologic hazard.

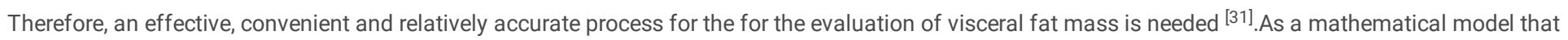
includes anthropometric and metabolic parameters, VAI is closely correlated with MRI-measured visceral adiposity, which is a useful indicator of adipose distribution ${ }^{[47]}$. Our study supplemented and confirmed the association between the VAI and carotid atherosclerosis in a general population, VAI could be selected as new and simple predictors of CAS for women aged $>44$.

The data of the present study were collected from tertiary general hospitals in Changsha, China. For the first time, the relationship between VAl and carotid atherosclerosis in different age groups and genders was evaluated, and self-reported data were the advantage of this study; In addition, the large sample size. However, the present study has several limitations: First, the study was conducted in a limited area of China (Changsha City), and may not represent China as a multi-ethnicity country; second, although the data of diet, exercise, and work pressure of some subjects were collected, these data were all from self-reported data, which have certain subjectivity; third, the present study was a cross-sectional study, which has certain limitations and cannot verify the causal relationship between VAl and carotid atherosclerosis. Finally, some related risk factors exist, such as endothelial cell function, the economic status of subjects, homocysteine levels were not collected and analysed in this study.

In conclusion, the present study has shown that the VAI may be associated with the risk of CAS in females, and it is more significant in women aged $>44$. However, this trend was not observed in men, and women aged $\leq 44$.

\section{Declarations}

\section{Authors' contributions}

JC contributed to the conception and design of this study. SL, QY,YZ andYZ were involved in the acquisition of data. JH and SL conducted the statistical analysis and interpretation of data. JC drafted the manuscript. JC, SL, QY and JH contributed to the revision of manuscript for important intellectual content. All authors read and approved the final manuscript.

\section{Declaration of Competing Interest}

The authors declare that they have no competing interests.

\section{References}


[1] Zhou M, Wang H, Zeng X, et al. Mortality, morbidity, and risk factors in China and its provinces, 1990-2017: a systematic analysis for the Global Burden of Disease Study 2017. Lancet 2019;394(10204):1145-1158. (PMID: 31248666).

[2]Qureshi, A. I. \& Caplan, L. R. Intracranial atherosclerosis. Lancet 2014;383: 984-998 . (PMID: 24007975).

[3]Li Y, Zhao D, Wang M, Sun JY, et al. Association of menopause with risk of carotid artery atherosclerosis.Maturitas.2021;Jan;143:171-177. (PMID: 33308625).

[4] Seven E, Thuesen BH, Linneberg A, et al. Abdominal adiposity distribution quantified by ultrasound imaging and incident hypertension in a general population. Hypertension(Dallas,Tex:1979).2016;68:1115-1122.(PMID: 27620395).

[5] Qin W,Liu F,Wan C.A U-shaped association of body mass index and al-I cause mortality in heart failure patients: a dose-response meta-analysis of prospective cohort studies .Cardiovascular Therapeutics 2017;35(2):1.(PMID: 27783461).

[6] Chen Liu,Lijun Zhang. New body fat index, lipid accumulation index and visceral fat index. Chinese Journal of diabetes 2016,24冈11):1032-1035. (PMID:28715064).

[7]Yusuf S, Hawken S, Ounpuu S et al.; INTERHEART Study Investigators. Obesity and the risk of myocardial infarction in 27,000 participants from 52 countries: a case-control study. Lancet 2005;366:1640-1649.(PMID:16271645).

[8]Romero-Corral A, Montori VM, Somers VK et al. Association of bodyweight with total mortality and with cardiovascular events in coronary artery disease: a systematic review of cohort studies. Lancet 2006;368:666-678. (PMID:16920472).

[9]Amato MC, Giordano C, Galia M,et a1.Visceral adiposity index:a reliable indicator of visceral fat function associated with cardiometabolic risk.Diabetes Care, 2010, 33 (4): 920-922.DOI:10.2337/dc09-1825.(PMID:20067971).

[10]Cornier MA,Despres JP,Davis N,et al.A ssessing adiposity:a scientific statement from the American Heart Association. Circulation. 2011; $124:$ 1996-2019. (PMID:21947291).

[11]Kim TH, Lee SS, Yoo JH, et al. The relationship between the regional abdominal adipose tissue distribution and the serum uric acid levels in people with type 2 diabetes mellitus. Diabetol Metab Syndr. 2012;4(1):3.(PMID:22301198). [12]JohnsonW,ChumleaWC,CzerwinskiSA,etal.Concordance of the recently published body adiposity index with measured body fat percent in European-American adults. Obesity(SilverSpring,Md). 2012;20:900-903.27. (PMID:22095112).

[13]LopezAA,CespedesML,VicenteT,etal.Body adiposity index utilization in a Spanish Mediterranean population: comparison with the body mass index. PloSOne. 2012;7:e35281.(PMID:22496915).

[14] Kahn Hs. The "lipid accumulation product"performs better than the body mass index for recognizing cardiovascular risk:a population based comparison. BMC Cardiovasc Disord,2005,5:26.(PMID:16150143).

[15]Stein JH, Korcarz CE, Mays ME, et a1.A semiautoumated ultrasound border detection program that facilitates clinical measurement of ultrasound carotid intima-media thickness.J Am Soc Echocardiogr,2005,18:244-251.(PMID:15746714). [16]Stary HC.Natural history and histological classification of atherosclerotic lesions:an update. Arterioscler Thromb VascBiol, 2000; 20(5): 1177-8. (PMID:10807728).

[17]World Health Day 2012:ageing and health:toolkit for event organizers.

[18] Whelton PK,Carey RM, Amnow WS, et a1.2017 ACC/AHA/AA-PA/ABC/ ACPM/AGS/APhA/ASH/ASPC/NMA/PCNA Guideline for the Prevention, Detection, Evaluation, and Mallagement of High Blood Pressure in Adults A Report on of the American College of Cardiology/American Heart Association Task Force on Clinical Practice Guidelines. Hypenension, 2018,71(6):e13-e115.(PMID:29133356).

[19] Liu PJ, Ma F, Lou HP, Chen Y. Visceral adiposity index is associated with pre-diabetes and type 2 diabetes mellitus in Chinese adults aged 20-50. Ann Nutr Metab 2016;68(4):235-43.(PMID:27161795).

[20] Bai R, Wu W, Dong W, et al.Forecasting the Populations of Overweight and Obese Chinese Adults.Diabetes Metab Syndr Obes. 2020 ;(8)13: $4849-4857$. (PMID:33324082).

[21] National Health and Family Planning Commission. Report on nutrition and chronic diseases of Chinese residents (2015) [EB / OL]. [2019-07-10] http://www.nhc.gov.cn/jkj/s5879/201506/4505528e65f3460fb88685081ff158a2.shtml.

[22] Wang Y, Wang L, Qu W. New national data show alarming increase in obesity and noncommunicable chronic diseases in China. Eur J Clin Nutr,2016,71(1):149-150. (PMID:27703162).

[23] Youfa Wang , Hong Xue, Mingxiao Sun , et al. Prevention and control of obesity in China.Lancet Glob Health,2019;7(9):e1166-e1167.(PMID:31401995).

[24] Defronzo RA. From the triumvirate to the ominous octet: a new paradigm for the treatment of type 2 diabetes mellitus.Diabetes 2009;58(4):773-95.

(PMID:19336687). 
[25] Despre's JP. Intra-abdominal obesity: an untreated risk factor for type 2 diabetes and cardiovascular disease. J Endocrinol Invest 2006;29(Suppl. 3):7782. (PMID:16751711).

[26] Hardy OT, Czech MP, Corvera S. What causes the insulin resistance underlying obesity? Curr Opin Endocrinol Diabetes Obes 2012;19(2):81-7. (PMID: 11460565 ).

[27]Dai D, Chang Y, Chen Y, Chen S, Yu S, Guo X, et al. Visceral adiposity index and lipid accumulation product index: two alternate body indices to identify chronic kidney disease among the rural population in Northeast China. Int J Environ Res Public Health 2016;13(12):1-11.(PMID: 27983609).

[28] Shen YY, Chen JC, Li G, et al. Relationship of lipid accumulation product with hypertension and diabetes among Beijing residents study. Zhonghua Yu Fang Yi Xue Za Zhi, 2017; 6(5):415-420.(PMID: 28464592).

[29]Amato, M. C. et al. Visceral Adiposity Index: a reliable indicator of visceral fat function associated with cardiometabolic risk. Diabetes care, 2010, 33:920922. (PMID: 20067971).

[30] Amato, MC, Giordano, C, Pitrone, M. \& Galluzzo, A. Cut-off points of the visceral adiposity index (VAI) identifying a visceral adipose dysfunction associated with cardiometabolic risk in a Caucasian Sicilian population. Lipids Health Dis , 2011,10:183 .(PMID: 22011564).

[31] Mohammadreza B, Farzad H, Davoud K囚et a1.Prognostic signifieance of the complex "Visceral Adiposity Index" vs.simple anthropometric measures $\rrbracket$ Tehran lipid and glucose study.Cardiovasc Diabetol,2012,11:20区(PMID: 22394430).

[32]Wang Y, Shi D, Chen L. Lipid profile and cytokines in hypertension of pregnancy: A comparison of preeclampsia therapies.Randomized Controlled Trial, 2018;20(2): 394-399.(PMID: 29316154).

[33] Xuan Zhong, Jing Ye, Chonghai Wu, et al. Relationship between visceral fat index and coronary heart disease and severity of coronary artery disease. Guangdong Medical Journal, 2014,35 (17): 2678-2681.(PMID: 31927390).

[34] Hen HY, Chiu YL囚Chuang YF, et al. Visceral adiposity index and risks of cardiovascular events and mortality in prevalent hemodialysis patients.Cardiovasc Diabetol,2014,13:136囚(PMID: 28315007).

[35] Ditomasso D, Carnethon MR, Wright CM, et a1.The associations between visceral fat and calcified atherosclerosis are stronger in women than men. Atherosclerosis $₫ 2010,208(2): 531-536 .(P M I D: 19765708)$.

[36] Rui Li, Qi Li, Min Cui, et al. Visceral adiposity index, lipid accumulation product and intracranial atherosclerotic stenosis in middle-aged and elderly Chinese. scientific reports.2017,11:7951.(PMID: 28801558).

[37]SATO T,MORI M,AOKI J, et al. Pulmonary tumor thrombotic microangiopathy due to advanced gastric cancer with virchow's node metastasis. Int Heart J,2018,59(2):443-447.(PMID: 29503403).

[38] OHGUCHI H,IMAEDA K,HOTTA A,et al.An autopsy case of pulmonary tumor thrombotic microangiopathy due to rapidly progressing colon cancer in a patient with type 2 diabetes. Intern Med, 2018, 57(17):2533-2539.(PMID: 29607944).

[39]Hoefle G,Saely $\mathrm{CH}$,Risch L,et al. Relationship between the adipose - tissue hormone resostin and coronary artery disease. Clin Chim Acta,2007,386(1 -2):1 -6.(PMID: 17706624).

[40] Kuk JL,Saunders TJ, Davidson LE, et al. Age-related changes in total and regional fat distribution. Ageing Res Rev,2009,8(4):339-348.(PMID: 19576300 ).

[41]Lin Ding , Kui Peng , Lin Lin, et al. The impact of fat distribution on subclinical coronary atherosclerosis in middle-aged Chinese adults. Int J Cardiol, 2017,5;(2):118-123.(PMID: 28274579).

[42] Kato A, Ishida J, Endo Y,et a1.Association of abdominal visceral adiposity and thigh sarcopenia with changes of arteriosclerosis in haemodialysis patients. Nephrol Dial Transplant,2011,26(6):1967-1976.DOI:10.1093/ndt/gfq652区

[43] Khashper A, Gaspar T, Axencot M,et a1.Visceral abdominal adipose tissue and coronary atherosclerosis in asymptomatic diabetics. Int Cardiol, 2013,162:184-188. (PMID: 21641054).

[44] Yoshinori Ozeki , Takayuki Masaki , Yuichi Yoshida, et al. Relationships between computed tomography-assessed density, abdominal fat volume, and glucose metabolism after sleeve gastrectomy in Japanese patients with obesity. Endocr J. 2019, 28;66(7):605-613.(PMID: 31019152).

[45] OHASHIN, YAMAMOTOH, HORIGUCHIJ ,et al. Association between visceral adipose tissue area and coronary plaque morphology assessed by ct angiography. JACC Cordiovascular imaging,2010,3(9):908-917.(PMID: 20846624).

[46] Gunisil Yalcin , Enes Ozsoy , Turgut Karabag .The relationship of body composition indices with the significance, extension and severity of coronary artery disease. Nutr Metab Cardiovasc Dis, 2020 ,27;30(12):2279-2285.(PMID: 32928627).

[47] Kouli GM, Panagiotakos DB, Kyrou I, Georgousopoulou EN, Chrysohoou C, Tsigos C, et al. Visceral adiposity index and 10-year cardiovascular disease incidence: the ATTICA study. Nutr Metabol Cardiovasc Dis NMCD ,2017;27: 881e9. (PMID: 28851556). 
Figures
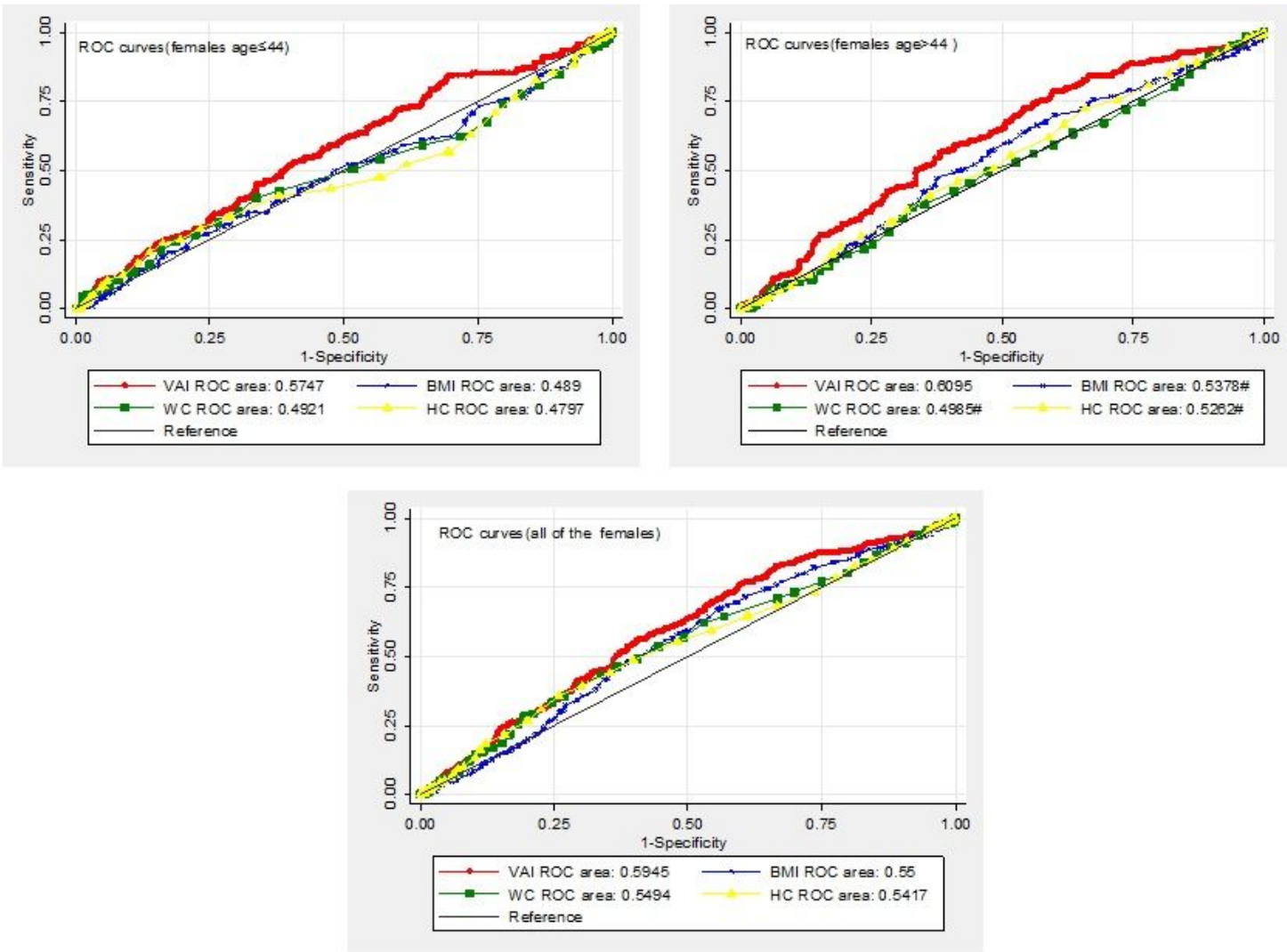

\section{Figure 1}

ROC of obesity indices (VAl, BMI, WC, HC) comparing the carotid atherosclerosis predictive values. A: ROC curves in the females aged $\leqq 44$ subgroup, B :ROC curves in the females aged $>44$ subgroup, $C: R O C$ curves in the all females subgroup \# The differences of AUC between VAl and the index were significant $(\mathrm{P}<0.001)$ 